\title{
A short neuropsychological evaluation of patients with primary Sjögren's syndrome
}

\author{
Avaliação neuropsicológica breve em pacientes com síndrome de Sjögren primária \\ Dóra-Neide Rodrigues', João Sergio Ignácio Hora², Maria Cecilia Fonseca Salgado², Renata Alves Paes4, \\ Claudia Cristina Ferreira Vasconcelos 5 , J. Landeira-Fernandez ${ }^{6}$, Regina Maria Papais Alvarenga
}

\begin{abstract}
Objective: To investigate cognitive deficits in patients with primary Sjögren's syndrome (PSS). Method: Eighteen patients with PSS, aged between 25 and 61 years, were subjected to a short neuropsychological battery and compared with 18 patients with multiple sclerosis and 18 healthy controls. Results: The analysis of variance (ANOVA) revealed that the clinical groups had significantly worse performance than the control group on the Rey Auditory Verbal Learning Test 3; $\left(F_{2.53}=3.500, p=0.038\right)$ and $7\left(F_{2.53}=5.068, p=0.010\right)$. The clinical groups had elevated levels of depression on the Beck Depression Inventory (BDI); $(p=0.003)$. The analysis of the data from the Trail Making Test B-A revealed a significant difference between the clinical and control groups $(p=0.023)$. The analysis of covariance with BDI score as a covariate, did not change the outcome. Conclusion: Our study revealed cognitive deficits in patients with PSS detectable by a short neuropsychological battery.
\end{abstract}

Keywords: neuropsychological evaluation; Sjögren's syndrome, cognitive impairment, neuropsychology.

\section{RESUMO}

Objetivo: Investigar déficits cognitivos em pacientes com síndrome de Sjögren primária (SSP) utilizando bateria neuropsicológica breve. Método: Dezoito pacientes com SSP e idade entre 25 e 61 anos, foram submetidos a uma bateria neuropsicológica breve e os resultados comparados com 18 pacientes com esclerose múltipla e com 18 controles saudáveis. Resultados: A análise da variância revelou que os grupos clínicos apresentaram desempenho significativamente pior que os controles ao Rey Auditory Verbal Learning Test 3 (RAVLT 3; $F_{2,53}=3,500$, $\mathrm{p}=0,038)$ e RAVLT $7\left(F_{2,53}=5,068, p=0,010\right)$. Os grupos clínicos apresentaram índices elevados de depressão pela Beck Depression Inventory (BDI); $\left(F_{2,53}=0.003\right)$. O desempenho no Trail Making Test B-A revelou diferença significativa entre os grupos clínicos e o grupo controle $(p=0,023)$. A análise de covariância tomando a BDI como covariante, não revelou mudanças nos resultados. Conclusão: Nosso estudo revelou comprometimento cognitivo em pacientes com SSP detectável por bateria neuropsicológica breve.

Palavras-chave: avaliação neuropsicológica; síndrome de Sjögren; comprometimento cognitivo; neuropsicologia.

Primary Sjögren's syndrome (PSS) is an inflammatory autoimmune disease characterized by infiltration of exocrine glands. It occurs without an association with other connective tissue diseases and affects mainly salivary and lachrymal glands, causing xerostomy and keratoconjunctivitis sic$\mathrm{ca}^{1,2}$. It often afflicts middle-age women, with an estimated prevalence of $2 \%$ in the adult population ${ }^{3}$. Moreover, PSS can be associated with impairments of the nervous system. In the central nervous system (CNS), the focal and nonfocal involvement of the brain and spinal cord has been described, resulting in a wide spectrum of neurological, psychiatric, and cognitive symptoms ${ }^{4}$.

Cognitive impairments in patients with PSS were reported by Malinow ${ }^{5}$ and later confirmed by other studies ${ }^{6,7}$. In Brazil, we have not found any case-series studies that have investigated cognitive impairments in PSS. We found one case report ${ }^{8}$.

The results from other countries suggest that patients with PSS display cognitive impairments in attention, memory,

\footnotetext{
Trabalho desenvolvido no Programa de Pós-Graduação em Neurologia, Universidade Federal do Estado do Rio de Janeiro, Rio de Janeiro RJ, Brazil. ${ }^{1}$ Neuropsicóloga, Mestre em Neurologia pela Universidade Federal do Estado do Rio de Janeiro, Rio de Janeiro RJ, Brazil; ${ }^{2}$ Reumatologista, Mestre em neurologia pela Universidade Federal do Estado do Rio de Janeiro, Rio de Janeiro RJ, Brazil; ${ }^{3}$ Professora associada, Chefe do Serviço de Reumatologia do Hospital Universitário Gaffréé e Guinle (HUGG- UNIRIO), Rio de Janeiro RJ, Brazil; ${ }^{4}$ Neuropsicóloga, Doutoranda em Neurologia pela Universidade Federal do Estado do Rio de Janeiro, Rio de Janeiro RJ, Brazil;

${ }^{5}$ Neurologista, Doutora em Neurologia pela Universidade Federal do Estado do Rio de Janeiro, Rio de Janeiro RJ, Brazil;

${ }^{6}$ Prof. Dr. Psicólogo, Professor da Pontifícia Universidade Católica Rio de Janeiro, Rio de Janeiro RJ, Brazil;

${ }^{7}$ Profa. Dra. Neurologista, Coordenadora dos Cursos de Mestrado e Doutorado em Neurologia da Universidade Federal do Estado do Rio de Janeiro, Rio de Janeiro RJ, Brazil. Correspondence: Dóra-Neide Rodrigues; Rua Almirante Tamandaré 66/445 / Flamengo; CEP 22210-060 Rio de Janeiro RJ - Brasil; E-mail: dcerq@uol.com.br Conflict of interest: There is no conflict of interest to declare.
}

Received 15 May 2013; Received in final form 26 August 2013; Accepted 02 September 2013. 
speed of information processing, and executive function, indicating a pattern of frontal-subcortical dysfunction'. Psychiatric alterations have also been reported to be associated with cognitive impairments related to diffuse encephalic manifestations ${ }^{5,10}$.

The present study investigated cognitive impairments in a cohort of patients with PSS from Rio de Janeiro using a short neuropsychological battery.

\section{METHODS}

\section{Subjects}

Patients with PSS and multiple sclerosis (MS) were recruited from the outpatient neurology and rheumatology services of the university hospital of Federal University of the state of Rio de Janeiro - Gaffree and Guinle University Hospital (HUGG) - from 2008 to 2010. Eighteen patients with PSS, according to the Modified European criteria from the American-European consensus ${ }^{1}$ were selected. Other eighteen MS patients were also selected, according to McDonald's ${ }^{11}$ criteria. As for MS patients, four exclusion criteria were applied in order to avoid interference with cognitive performance: 1- marked visual impairment with a maximum corrected visual acuity in the most affected eye of 20/100 to 20/200 (0.2-0.1) and score on the Expanded Disability Status Scale (EDSS) $\geq 8$ (i.e., patients with severe motor impairment restricted to bed or to a wheelchair and decreased function of upper limbs), 2- acute attacks, 3- use of psychoactive substances and 4- coexistence of other clinical conditions (e.g., altered thyroid hormone, hypertension, human immunodeficiency virus, syphilis and other neurological or psychiatric disorders). Criteria 3 and 4 were also considered exclusion criteria for the PSS patients group. Researchers invited eighteen community participants as healthy controls. They had no association with the hospital.

\section{Neuropsychological evaluation}

The battery used in the present study included tests that are sensitive to changes in frontal dysfunction, executive function, attention, verbal memory, and visuospatial function. The evaluation of auditory memory included parts of working memory, learning ability, short- and long-term (i.e., $15 \mathrm{~min}$ ) recall, and recognition and was performed using the Rey Auditory Verbal Learning Test (RAVLT) ${ }^{12}$.

From a list of 15 words, the patient was asked to repeat the words five consecutive times after verbalization by the examiner. A list for distraction was then presented. After its recall, the patient was requested to repeat the first list of words. Fifteen minutes later, the patient was asked to recall the first list again and then offered a list of 30 words from which the patient needed to recognize the original words of the first list.
The oral form of the Symbol Digit Modalities Test $(\mathrm{SDMT})^{13}$ was used to measure attention. This test consisted of presenting the patient with a sheet with numbers associated with symbols. The patient needed to identify and verbalize the number that should be placed in the space provided.

Part A form of the Trail Making Test (TMT-A) was also used $^{12}$. This test consisted of presenting the patient with a sheet that contained an ascending sequence of numbers within circles. The patient needed to connect the numbers in ascending order as fast as possible while the examiner recorded the time.

Language was measured using the semantic (i.e., animals and fruits) and phonemic (i.e., for the letters F, A, and S) modalities of the Controlled Oral Word Association Test $(\text { COWAT })^{12}$. The patient was asked to speak the names of animals as many times as possible in $1 \mathrm{~min}$. The same procedure was repeated with fruits and the letters F, A, and S.

The Hooper Visual Organization Test (HVOT) $)^{14}$ was used to evaluate visuospatial function. The patient was presented with a notebook with figures cut in pieces. The patient needed to mentally manipulate the pieces and speak the name of the formed figure.

Executive function was measured using the COWAT, TMT part B and TMT part B minus A (TMT B-A). The administration of the TMT $B$ consisted of presenting a sheet with a sequence of numbers and letters. The patient needed to link alternating numbers with a straight line in ascending order and letters in alphabetic order. The examiner recorded the time needed to finish the task. After the measurements of cognitive function, the Beck Depression Inventory (BDI) was used to measure the levels of depressive symptoms ${ }^{15}$. The evaluations were performed individually in an utpatient neurology clinic at HUGG. Trained neuropsychologists applied the tests, performed corrections, and interpreted the results.

\section{Statistical analysis}

The Statistical Package for Social Sciences (SPSS 18) was used to analyze the data. All of the neuropsychological variables were normally distributed, verified by the Kolmogorov-Smirnoff test. The neuropsychological measures of depression were compared between the three groups using analysis of variance (ANOVA) and by post-hoc test. The neuropsychological variables assessed by the TMT were compared between two groups (PSS and control) using Student's $t$-test. An analysis of covariance (ANCOVA), adjusted for the effect of depression and was used when a neuropsychological variable was significantly correlated with depression. The LSD multiple comparisons test was used for post hoc comparisons whenever a significant effect was detected by the ANOVA or ANCOVA. The results are presented as means and standard deviations, the $p$ values are presented in Tables 1 and 2 and post-holc results in Table 3. 
Table 1. Mean, standard deviation (SD) and percentile of demographic variables.

\begin{tabular}{|c|c|c|c|c|}
\hline \multirow{2}{*}{ Variable } & \multicolumn{4}{|c|}{ Mean (SD) $)^{*}$ and $\%^{* *}$} \\
\hline & PSS $(n=18)$ & MS $(n=18)$ & Control $(n=18)$ & $\mathrm{p}$-value \\
\hline Age & $49.7(11.7)$ & $49.3(10.7)$ & $49.9(10.9)$ & 0.986 \\
\hline Years of education & $10.3(3.3)$ & $10.8(3.9)$ & $10.6(3.5)$ & 0.933 \\
\hline Sex female & $18(100 \%)$ & $18(100 \%)$ & $18(100 \%)$ & \\
\hline
\end{tabular}

PSS: primary Sjogren's syndrome; MS: multiple sclerosis.

Table 2. Mean and standard deviation (SD) of neuropsychological variable and depression.

\begin{tabular}{|c|c|c|c|c|}
\hline \multirow{2}{*}{ Variable } & \multicolumn{3}{|c|}{ Mean (SD) } & \multirow{2}{*}{$\mathrm{p}$-value } \\
\hline & PSS $(n=18)$ & MS $(n=18)$ & Control $(n=18)$ & \\
\hline \multicolumn{5}{|l|}{ Attention } \\
\hline SDMT & $41.9(16.9)$ & $37.0(15.9)$ & $44.3(13.9)$ & 0.364 \\
\hline SDMT error & $1.4(1.5)$ & $1.5(2.0)$ & $0.94(1.3)$ & 0.550 \\
\hline TMT A & $75.1(31.9)$ & - & $71.9(28.6)$ & 0.752 \\
\hline \multicolumn{5}{|l|}{ Executive function } \\
\hline Phonemic fluency & $34.0(10.6)$ & $36.2(14.5)$ & $40.3(14.2)$ & 0.355 \\
\hline Semantic fluency & $31.6(7.6)$ & $30.2(9.6)$ & $34.5(9.1)$ & 0.334 \\
\hline TMT B & $166.0(78.2)$ & - & $129.8(59.5)$ & 0.127 \\
\hline TMT B-A & $91.4(51.4)$ & - & $56.3(35.7)$ & 0.023 \\
\hline \multicolumn{5}{|l|}{ Memory } \\
\hline RAVLT 1 & $4.2(1.3)$ & $5.1(1.9)$ & $5.3(1.2)$ & 0.089 \\
\hline RAVLT 2 & $6.8(1.8)$ & $7.6(2.5)$ & $7.6(1.9)$ & 0.485 \\
\hline RAVLT 3 & $8.6(2.3)$ & $8.8(2.0)$ & $9.8(1.2)$ & 0.038 \\
\hline RAVLT 4 & $9.3(2.7)$ & $9.5(2.2)$ & $11.1(1.7)$ & 0.105 \\
\hline RAVLT 5 & $10.7(2.6)$ & $10.3(2.1)$ & $11.9(1.7)$ & 0.080 \\
\hline RAVLT total & $39.2(9.5)$ & $41.3(9.5)$ & $45.4(4.9)$ & 0.082 \\
\hline RAVLT span & $6.3(2.5)$ & $5.2(2.1)$ & $6.50(2.0)$ & 0.154 \\
\hline RAVLT 6 & $8.0(3.4)$ & $8.2(2.6)$ & $10.7(2.6)$ & 0.088 \\
\hline RAVLT 7 & $8.6(3.8)$ & $7.8(2.8)$ & $11.2(2.2)$ & 0.012 \\
\hline RAVLT recognition & $26.6(3.2)$ & $26.9(2.1)$ & $28.3(1.9)$ & 0.083 \\
\hline \multicolumn{5}{|l|}{ Visuospatial function } \\
\hline HOOPER & $20.3(5.2)$ & $17.8(6.2)$ & $20.9(4.3)$ & 0.189 \\
\hline \multicolumn{5}{|l|}{ Depression } \\
\hline $\mathrm{BDI}$ & $14.2(6.0)$ & $13.8(19.8)$ & $6.2(3.5)$ & 0.003 \\
\hline
\end{tabular}

\section{RESULTS}

The demographic variables are shown in Table 1. The ANOVA did not reveal any significant difference in age $\left(\mathrm{F}_{2,53}=0.90, \mathrm{p}=0.986\right)$ or education $\left(\mathrm{F}_{2,53}=0.070, \mathrm{p}=0.933\right)$ between the clinical and control groups.

The neuropsychological and depression variables are shown in Table 2. The ANOVA did not reveal significant group differences in the tasks used to quantify attention and speed of information processing, reflected by total scores on the SDMT $\left(\mathrm{F}_{2,53}=1.030, \mathrm{p}=0.364\right)$ and average error $\left(\mathrm{F}_{2,53}=0.606, \mathrm{p}=0.550\right)$.

Student's two-tailed t-test did not reveal significant differences in performance on the TMT A between the PSS and control groups $(\mathrm{p}=0.752)$. In the performance on the TMT B, no significant differences were found between the PSS and control groups ( $\mathrm{p}=0.127$ ). The analysis of the TMT B-A revealed a significant difference between the PSS and control groups ( $p=0.023)$, indicating that patients with PSS had inferior performance in conceptual flexibility compared with healthy controls.

For the verbal fluency analysis, the ANOVA did not reveal significant differences in phonemic fluency $\left(\mathrm{F}_{2.53}=1.056\right.$, $\mathrm{p}=0.355)$ or semantic fluency $\left(\mathrm{F}_{2,53}=1.120, \mathrm{p}=0.334\right)$ between the three groups.

For performance on the memory test, the ANOVA revealed a significant difference between the PSS and control groups for word recall in step $3\left(\mathrm{~F}_{2,53}=3.879, \mathrm{p}=0.027\right)$ and step $7\left(\mathrm{~F}_{2,53}=6.315, \mathrm{p}=0.004\right)$ Table 3 .

The ANOVA did not reveal significant group differences in performance on the Hooper $\left(\mathrm{F}_{2,53}=1.724, \mathrm{p}=0.189\right)$ by post -hoc 667 (,707) between PSS and control group. 


\begin{tabular}{lccc}
\hline \multirow{2}{*}{ Variable } & & Mean difference and significance level & MS / control \\
\cline { 2 - 3 } Age & PSS / MS & PSS / control & $0.611(0.870)$ \\
Years of study & $0.389(0.917)$ & $0.222(0.953)$ & $0.167(0.890)$ \\
SDMT & $0.444(0.715)$ & $0.278(0.818)$ & $7.333(0.165)$ \\
SDMT error & $4.944(0.347)$ & $-2389(0.649)$ & $0.556(0.322)$ \\
Phonemic fluency & $0.56(0.921)$ & $0.500(0.373)$ & $4111(0.357)$ \\
Semantic fluency & $2.222(0.617)$ & $6.333(0.158)$ & $4.333(0.148)$ \\
RAVLT 1 & $1.444(0.626)$ & $2.889(, 0.332)$ & $167(0.742)$ \\
RAVLT 2 & $889(0.084)$ & $1.056(0.041)$ & $192(0.833)$ \\
RAVLT 3 & $825(0.092)$ & $1.012(0.055)$ & $1.000(0.124)$ \\
RAVLT 4 & $0.778(0.230)$ & $1.778(0.008)$ & $1.611(0.032)$ \\
RAVLT 5 & $167(0.821)$ & $1.788(0.019)$ & $1.611(0.032)$ \\
RAVLT Total & $0.389(0.597)$ & $1.222(0.100)$ & $4.056(0.147)$ \\
RAVLT Span & $2.167(435)$ & $6.222(0.028)$ & $1.333(0.076)$ \\
RAVLT 6 & $1.167(0.119)$ & $0.167(0.822)$ & $2.444(0.015)$ \\
RAVLT 7 & $222(0.819)$ & $2.667(0.008)$ & $3.389(0.001)$ \\
RAVLT Recognition & $0.778(0.440)$ & $2.611(0.012)$ & $1.389(0.096)$ \\
HOOPER & $389(0.637)$ & $1778(0.034)$ & $03111(0.084)$ \\
BDI & $2.444(0.172)$ & $667(0.707)$ & $7.611(0.003)$ \\
\hline SDMT: Symbi Digt Moda) & $8.56(0.002)$ & \\
\hline
\end{tabular}

SDMT: Symbol Digit Modalities Test; RAVLT: Rey Auditory Verbal Learning Test; HVOT: Hooper Visual Organization Test; BDI: Beck Depression Inventory; PSS: primary Sjogren's syndrome; MS: multiple sclerosis.

The ANOVA revealed a significant difference between the clinical and control groups in the levels of depression measured by the BDI $\left(\mathrm{F}_{2,53}=6.696, \mathrm{p}=0.003\right)$. The multiple comparison by post-hoc - LSD test, clinical groups showed higher rates of depression than control group $(\mathrm{p}=0.003)$ However, the difference between PSS and MS was not statistically significant $(\mathrm{p}=0.858)$.

\section{DISCUSSION}

Our study showed that patients with Sjögren's syndrome (SS) performed more poorly in executive functioning and long-term memory tests than healthy controls. The TMT B-A revealed a significant difference between the SS group and healthy controls, suggesting that SS patients had worse performance than healthy controls regarding conceptual flexibility. The performance on RAVLT 3 and 7 was significantly worse in the PSS group, revealing long-term memory changes.

PSS is associated with variable and nonspecific neurological manifestations that can be divided into focal, nonfocal, and spinal symptoms. Focal symptoms include sensorial and motor deficits, brainstem syndrome, movement disorders, cerebellum syndrome, seizures, and migraine. Nonfocal symptoms include encephalopathy, aseptic meningitis, cognitive dysfunction, dementia, and psychiatric disorders ${ }^{2}$. No consensus has been reached about the most common CNS manifestations of this disease. According to Malinow et al. ${ }^{5}$, the most common manifestations are nonfocal including cognitive impairments. As suggested by Tobon et al. ${ }^{16}$, nonfocal (diffuse) manifestations can be subdiagnosed according to the lack of a specific diagnosis modality.

Neuropsychological tests are used for the valid and sensitive detection of cognitive alterations associated with brain diseases, including PSS. However, no uniformity of protocols that are used to measure cognitive impairments, such as fatigue symptoms, is found in the literature.

Some studies, such as Chang ${ }^{3}$ and Delalande ${ }^{17}$, reported the presence of cognitive impairments in this population, but they did not describe the specific neuropsychological tests used. Among the studies that have used neuropsychological tests, Mataró et al. ${ }^{18}$, Martinez et al. ${ }^{7}$, and Segal et al. ${ }^{19}$ used extensive batteries composed of approximately nine neuropsychological tests. The present study followed the design of Martinez et al. ${ }^{7}$, with slight modifications, such as a reduction of the number of tests. Studies of patients with fatigue symptoms, such as MS, suggest the use of neuropsychological batteries with a reduced number of tests and time of application between 20 to $40 \mathrm{~min}^{20,21}$. Since fatigue is a commonly seen symptom in SSP patients, a briefer battery was used in the present study. The battery was composed of four tests and evaluated short and long-term declarative memory, attention, speed of information processing, executive function, verbal fluency, and visuospatial organization.

Memory and executive function are the most common cognitive alterations observed in PSS $^{22,18,23}$. In the present study, we found a significant difference in cognitive performance between PSS patients and controls in conceptual flexibility (i.e., inhibition control), one aspect of executive function. We also found a significant difference in performance 
between the clinical and control groups in tasks of immediate memory recall and long-term memory. As Table 2 shows in items 2,4,5 and 6 of RAVLT test the difference between controls and PSS patients was close to the significance level (borderline). We believe that a larger sample could help understand the difference between the performance of PSS and healthy controls in other parts of the test; thus, confirming that PSS Brazilian patients show critical memory impairment, as presented in other studies ${ }^{22,18,23}$.

We did not observe a significant difference between the clinical and control groups in verbal fluency on the Hooper, another task that measures aspects of executive function. The SDMT, which measures the speed of information processing, has been the first choice for measuring this function in patients with $\mathrm{MS}^{24}$ and has confirmed cognitive slowing in these patients. In the present study, we did not observe significant differences in performance between the clinical and control groups on the SDMT. We believe that this result might be influenced by the present sample size $(n=18)$. A larger sample size might clarify this issue.

Despite the similarity in performance on the memory tests between the PSS and MS groups, indicating cortical impairment, Table 2 shows low performance in the speed of information processing in the MS group compared with the PSS group, suggesting increased subcortical alterations.

In semantic fluency, the MS group displayed worse performance compared with the PSS group. However, in phonemic fluency, a subtest that evaluates executive function, the PSS group displayed worse performance compared with MS patients and controls, indicating increased alterations in functions that depend on the integrity of the frontal lobe 9 .
On the TMT, which evaluates focused and alternated attention and the ability to inhibit external interference, only the most sensitive aspect of frontal lobe function was compromised in the PSS group, which is consistent with the literature. On the TMT B-A, the PSS group performed significantly worse than the control group, indicating frontocortical alterations. We were unable to compare the PSS and MS groups on the TMT because MS patients were not subjected to this test.

Cognitive impairments in PSS and MS patients is a relevant issue because both pathologies present CNS difuse changes. Future studies will clarify whether distinct cognitive patterns exist between these diseases.

Psychiatric and mood manifestations have been widely reported in patients with PSS ${ }^{16,25}$. In the present study, we found increased levels of depressive symptoms in the clinical groups evaluated by the BDI, corroborating the literature.

Depression is a variable that might affect cognitive performance. However, Martinez et $\mathrm{al}^{7}$ controlled this by using the proper statistical treatment. We have used Ancova. The depression level was used as a covariate and it did not change the outcome with regard to cognitive performance between the clinical and control groups.

In conclusion, the present study showed that the clinical groups performed worse than the control group on all of the tests, and patients with PSS exhibited impairments in executive function and memory, confirming previous studies. Future studies with large sample and specific tests for PSS are necessary to better characterize the cognitive profiles in this population.

\section{References}

1. Vitali C, Bombardiere S, Jonsson R, et al. Classification criteria for Sjögren's syndrome: a revised version of the European criteria proposed by the American-European Consensus Group. Ann Rheum Dis 2002;61:554- 558.

2. Fauchais AL, Magy L, Vidal E. Central and peripheral neurological complications of primary Sjögren's syndrome. Presse Med 2012;41:485-493.

3. Chang CP, Shiau YC, Wang JJ, Ho ST, Kao A. Abnormal regional cerebral blood flow on $99 \mathrm{mTC}$ ECD brain SPECT in patients with primary Sjögren's syndrome and normal findings on brain magnetic resonance imaging. Ann Rheum Dis 2002;61:774-778.

4. Govoni M, Padovan M, Rizzo N, Trotta F. CNS involvement in primary Sjögren's syndrome: prevalence, clinical aspects, diagnostic assessment and therapeutic approach. CNS Drugs 2001;15:597-607

5. Malinow KL, Molina R, Gordon B, Selnes O, Provost TT, Alexander EL. Neuropsychiatric dysfunction in primary Sjögren's syndrome. Ann Intern Med 1985;103:344-350.

6. Belin C, Moroni C, Caillat-Vigneron N, et al. Central nervous system involvement in Sjögren's syndrome: evidence from neuropsychological testing and HMPAO-SPECT. Ann Intern Med 1999;150:598-604.
7. Martinez S, Cáceres C, Mataró M, Escudero D, Latorre P, Dávalos A. Is there progressive cognitive dysfunction in Sjögren's syndrome? A preliminary study. Acta Neurol Scand 2010;122:182-188.

8. Brito GNO, Araujo GRB, Papi JA. Neuropsychological, neuroimage and psychiatric aspects of primary Sjögren's syndrome. Arq Neuropsiquiatr 2002;60:28-31.

9. Lafitte C, Amoura Z, Cacoub P. Neurological complications of primary Sjögren's syndrome.J Neurol 2001;248:577-584.

10. Seze J, Delalande S, Vermersch P. Les manifestations neurologiques du Gougerot-Sjögren. Rev Med Intern 2005;26:624-636.

11. Mcdonald WI, Compston A, Edan et al. Recommended diagnostic criteria for multiple sclerosis: guidelines from the International Panel on the Diagnosis of Multiple Sclerosis. Ann Neurol 2001;50:121-127.

12. Spreen O, Strauss E. A compendium of neuropsychological tests: administration, norms, and commentary, 2nd edition. New York: Oxford University Press, 1998:03-736.

13. Smith A. Symbol Digit Modalities Test. Los Angeles: Western Psychological Services, 1973:1-22.

14. Hooper H.E. The Hooper V sual Organization Test (VOT). Los Angeles: Western Psychological Services, 1983:1-32. 
15. Jurema AC. Manual da versão em Português das Escalas BECK. Casa do Psicólogo Livraria e Editora Ltda, São Paulo 2001:1-171.

16. Tobon GJ, Pers JO, Devauchelle-pensec V, Youinou P. Neurological disorders in primary Sjögren's syndrome. Autoimmune Dis 2012;2012:1-11.

17. Delalande S, DE Seze J, Fauchais AL, et al. Neurologic manifestations in primary Sjögren's syndrome: a study of 82 patients. Medicine 2004;83:280

18. Mataró M, Escudero D, Ariza M, et al. Magnetic resonance abnormalities 291. associated with cognitive dysfunction in primary Sjögren's syndrome. J Neurol 2003;250:1070-1076.

19. Segal BM, Pogatchnik B, Holker E. Primary Sjögren's syndrome: cognitive symptoms, mood, and cognitive performance. Acta Neurol Scand 2012;125:272-278.

20. Beatty WW, Paul RH, Wilbanks SL, Hames KA, Blanco CR, Goodkin DE. Identifying multiple sclerosis patients with mild or global cognitive impairment using the Screening Examination for Cognitive Impairment (SEFCI). Neurology 1995;45:718-723.

21. Solari A, Mancuso L, Motta A, Mendozzi LC. Comparison of two brief neuropsychological batteries in people with multiple sclerosis. Mult Scler 2002;8:169-176.

22. Le Guern V, Belin C, Henegar et al. Cognitive function and $99 \mathrm{mTc}-\mathrm{ECD}$ brailn SPECT are significantly correlated in patients with primary Sjögren's syndrome: a case-control study. Ann Rheum Dis 2010;69:132-137.

23. Mauch E, Volk C, Kratzsch G. Neurological and neuropsychiatric dysfunction in primary Sjögren's syndrome. Acta Neurol Scand 1994;89:31-35

24. Parmenter BA, Winstock-Guttman B, Garg N, Munschauer F, Benedict RHB. Screening for cognitive impairment in multiple sclerosis using the Symbol Digit Modalities Test. Mult Scler 2007;13:52-57.

25. Alexander el, Beall SS, Gordon B et al. Magnetic resonance imaging of cerebral lesions in patients with the Sjögren's syndrome. Ann Intern Med 1988;108:815-823. 